DOI: $10.21554 / \mathrm{hrr} .041912$

\title{
THE NATURE OF THE CHINESE SCRIPT
}

Jin Xiaolei ${ }^{1}$

Department of Oriental Studies, Faculty of Philology, Belgrade University, Serbia
Review scientific paper

Received: 2019/1/12

Accepted: 2019/3/20

\begin{abstract}
This paper introduces the nature of the Chinese script, with the focus on its origin and development, the main four kinds of creation methods, the basic strokes of Chinese characters and the significance of its radical structure. The author believes that Chinese characters are the carriers of the script, phoneme and meaning as well as of the grammatical structure of the Chinese language. Hence, the Latin alphabet for the Chinese phonetic system cannot replace Chinese character, and learning Chinese character is very important for foreign learners. Finally, the author gives a mnemonic of the basic rules for stroke order that facilitates learners' memory and helps them write characters correctly and quickly. Key Words: Chinese script, characters, strokes order, Chinese language
\end{abstract}

Script is the essence of the Chinese language. For centuries, it has stored in itself what is most precious in the Chinese civilization, culture and literature. In addition, the Chinese script acts as the connective tissue between the many peoples who live on the territory of PR China.

In the long history of the development of the Chinese script, there were periods when up to 60,000 characters were in use. Of course, if we eliminate the alternative written forms of characters for the same word, and if we exclude the ones already "dead", i.e. no longer used, today there are around ten to twenty thousand characters in constant use. Over the centuries, Chinese characters evolved not only in their form, but also in their meaning, pronunciation and usage. What we can say with certainty is that it is much more difficult to identify their pronunciation than to discern their meanings or patterns of usage in the ancient times of Chinese history. Namely, one and the same character was pronounced differently in different periods of history, and today we encounter a similar situation in the numerous Chinese dialects. It is therefore very common in China to see Chinese people, who come from areas in which different dialects are spoken, communicate by writing out characters, as none of them speaks "Mandarin Chinese", or the so-called Putonghua standard spoken language.

Most Chinese characters are formed in one of the four following ways:

First, there are pictographic characters (xiàngxíngzi) which make up about $5 \%$ of the total number of characters. With their stylized forms they directly point at objects and numerous other phenomena of the world.

\footnotetext{
${ }^{1}$ Correspodence to:

Jin Xiaolei, Department of Oriental Studies, Faculty of Philology, Belgrade University, Serbia

E-mail: xiaolei_jin@hotmail.com
} 


\section{sun

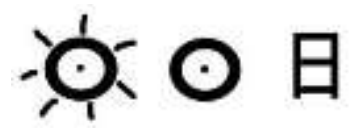 \\ moon

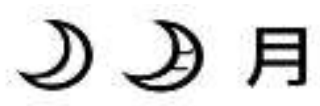

The second are indicative characters (zhǐyì) which express an abstract meaning through symbols. Not many characters belong to this category.

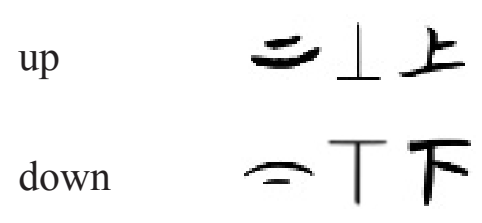

Associative compounds (huìyi) form the third category. This type of characters is the result of the combination of two or more elements, which creates new characters with new meanings.

$$
\begin{aligned}
& \text { light 明 } \\
& \text { good 好 }
\end{aligned}
$$

The fourth category, to which most characters belong, are the pictophonetic characters (xíngshēng); they make up over $80 \%$ of the total number of characters. In their structure, they have a pictographic element which points at the meaning and the phonetic element which directly refers to the pronunciation. E.g.:

$$
\begin{aligned}
& \text { mom 妈妈 } \\
& \text { river 河 }
\end{aligned}
$$

From the above examples, it is not hard to conclude that characters, however complicated in their writing, are rather simple when it comes to recognizing their meaning.

Chinese characters are "compounds" of strokes. Strokes form basic components which are constituent parts of characters. There are 540 basic components in total, and the difficulties in the computer processing of information in Chinese are significantly reduced thanks to them.
Thus the ancient Chinese script with its five-thousandyear-long history smoothly entered the E-age. Let us take a look at the basic strokes in the Chinese script:

horizontal
vertical
falling leftwards
dot
falling rightwards
break

There are about thirty types of strokes in total, which are organized on the basis of the above basic strokes. Simplified Chinese characters have about ten strokes on average, whereas characters of a more complex structure consist of around twenty-five strokes. According to the place of components in their structure, Chinese characters are divided into four groups:

1. characters with an independent structure (3\%), which consist of a single component. Such characters are: 女、子

2. characters with a left-right structure $(65 \%)$, two basic components are on the left and right side respectively. Such characters are: 汉、好

3. characters with a top-bottom structure (23\%), two basic components are in the top and the bottom part of the character respectively. Such characters are: 学、字

4. characters with an enclosed structure (9\%), two basic components are in the outer and the inner part of the character respectively. Such characters are: . 国、回.

When writing characters, it is necessary to follow the correct stroke order. This is important for a number of reasons, since on the one hand the right order of strokes helps us write characters correctly and quickly, and on the other facilitates searching for unfamiliar characters in a dictionary. 


\section{Stroke Order Song}

From left to right go, From top to bottom flow, Heng before shu, $\mathrm{Na}$ after pie,

First in the centre write, Then add strokes on either side.

First the upper, then the lower part. First to the left and then to the right. First the outside and then the inside, Finally close, you've done it quite right. Learn the order of strokes by heart And write characters well from the start.

The Chinese language is one of the few languages whose phonetic system ${ }^{2}$ is completely independent of its script. Even though we can sometimes have a vague idea of the pronunciation of a pictophonetic character, we will still not be able to know precisely how to read it, even less to determine the tone in which it is pronounced. This is also one of the particular difficulties in learning the Chinese language ${ }^{3}$. It is interesting that the Romanization system ${ }^{4}$ for the Chinese language was first "devised" by foreigners 5 . The Romanization system in use today was proposed by the Committee for Language Reform and verified by the Chinese National People's Congress in 1958. Since its adoption as the international standard (ISO 7098) in 1982, it has been used worldwide as the standard form for Chinese transcription. However, we have to bear in mind that the Chinese phonetic alphabet is only a tool and aid in the pronunciation of Chinese characters
That is, Romanization is only a system of symbols for the representation of speech sounds; it is not an alphabetic script (an all-phonemic language). Therefore, it can in no way be a substitute for the Chinese script. During the history of the modernization of the Chinese language, campaigns for the "Romanization of the Chinese script" were organized with the aim to simplify the script in order to reduce illiteracy. Luckily, however, in the 1980s, the Chinese government took the stance that it is important to maintain the continuity and stability of the language and gave up the plan for the complete "Romanization of the Chinese script".

As every word and expression in the Chinese language is linked to a Chinese character, it is natural that "composition" as the principal method of forming Chinese characters has also become the principal grammatical means of generating language expressions. The profound significance of Chinese characters in the Chinese language is also evident from the fact that they are the carriers of the script, phoneme and meaning as well as of the grammatical structure of the Chinese language.

\section{REFERENCES}

Boltz, W. G. (1994). The origin and early development of the Chinese writing system. New Haven: American Oriental Society.

Hu, Y. (1962/1981). Xiandai Hanyu. Shanghai: Shanghai jiaoyu chubanche. 169-231.

Karlgren, B. (1949). The Chinese language. New York: Ronald Press

Wang, L. (1954/2004). Hanyu Shigao. Beijing: Zhonghua shuju. 39-44.

Wang, Hongyuan (1993). The Origins of Chinese characters. Beijing: Sinolingua

${ }^{2}$ In the standard Chinese phonetic system (Putonghua), there are twenty-one consonants and thirty-nine vowels, among which six simple vowels. The Chinese language is also a tonal language which has four tones and one neutral tone.

${ }^{3}$ Sometimes, even if we do not know how to pronounce a certain character, it is still possible, with a little knowledge of the structure of the Chinese script, to "read" its meaning due to its pictorial forms.

${ }^{4}$ That is Pinyin, i.e. the Latin alphabet for the Chinese phonetic system.

${ }^{5}$ In 1605, the Jesuits Matteo Ricci and Lazzaro Cattaneo wrote Wonders of the Western Script, the book in which the Romanization of Chinese characters appeared for the first time; later, in 1626, building on Ricci's work and with the help of Chinese assistants, the Frenchman Nicolas Trigault compiled the first Romanization-based Chinese dictionary. 